\title{
THE NEW PARADIGM OF MEDICAL ENGLISH TEACHING AT THE UNIVERSITY LEVEL
}

\author{
JANINA WIERTLEWSKA
}

\begin{abstract}
Currently practised methods of medical English instruction at tertiary education level often focus on medical terminology embedded in the English language classes. These strategies which comprise medical terminology and simple dialogues do not meet the needs of highly qualified medical health care workers (doctors, nurses, paramedics and many others). The new paradigm claims that medical English should be taught from the perspective of medicine and health care first and reinforced by the vocabulary acquisition; first - teach the students standards of medical practice (anatomy, pharmacology, physiology, medical sciences. and behavioural/ethical procedures), later on - concentrate on medical communication (see: M. Hull, 2004). The following paper concentrates on both formerly mentioned parameters; and also includes student and teacher motivation. Further, language acquisition as well as language learning are discussed. The new paradigm is defined as a combination of academic preparation which comprises cognitive and behavioural approaches that appear to be secondary to the context of the given class. Students are encouraged to search for synonyms, abbreviations and alternative ways of expressing meaning to communicate with each other. They also prepare their own multimedia presentations in the group and deliver speeches on subjects contained in curriculum. Concluding, the author of this paper expresses the opinion that foundational underpinnings of the curriculum of the Medical English course should be linked to the parameters for the health care professions. Context of the classes needs to be relevant to the work of the health professionals (according to Pratt and others, 2002). Over the last 10 years the paradigm for medical English teaching in North America and West European countries has changed enormously and has started to pave its new way at tertiary education level in Poland as well, which is presented briefly in this paper and - hopefully will continue to develop according to the newly occurring phenomena.
\end{abstract}

Key words: medical English, English for Specific Purposes, university level 


\section{What are Languages for Specialist Purposes (LSPs)}

There are many definitions of languages for specialist purposes but some of them seem to be more interesting than others. According to Sofija Micic (2013) specialized languages are associated to a specific discourse that professionals and specialists use to communicate in order to transfer information and knowledge. Based on Widdowson (1997) it may be assumed that English, being used this way, is always the language for specific purposes. The study of languages for specific purposes represents a synthesis of linguistics and methodology of teaching foreign languages (L2) and includes the aspects of lexicology, terminology, translation and discourse analysis. Occupational registers provide a relevant code for the transfer of information among specialists in a given working niche. In this paper it is attempted to put together the theory and practice of languages for specific purposes.

\section{1a. English for Specific Purposes}

When looking back at the $19^{\text {th }}$ and the $1^{\text {st }}$ half of the $20^{\text {th }}$ centuries French and German languages dominated as lingua franca in Europe and this changed only after the end of the World War $2^{\text {nd }}$. The relevance of English in academic and professional settings began in the 1960s of the previous century and is still developing. Citing after Orr (2002:1) ESP ...is an exciting movement in English language education that is opening up rich opportunities for English teachers and researchers in new professional domains. Following this path further on, one can consider DudleyEvans and St John's (1998: 19) words about ESP being closely interlinked with Applied Linguistics and English Language Teaching. For most of its history ESP has been dominated by English for Academic Purposes (EAP) with its subspecialty English for Science and Technology (EST, Swales, 1988). Nowadays EAP and ESP are commonly referred to as International Scientific English (ISE). According to Wood (2001: 81-83) English is perceived as ISE and as such it forms a part of science and it therefore forms an integral part of becoming a scientist.

\section{ESP/Medical English}

Some authors (Mc Cullagh, 1989; and Mintz, 1992) have described medical language as an abstract discourse about disease and organs and emphasized its distancing function. Other researchers (Crookshank, 1923; Cassell, 1976) expressed their opinion of medical language as the one describing lexis of diseases which were treated as static entities rather than dynamic processes. In the past two centuries epochal discoveries have been made in medicine and the new branches (e.g. molecu- 
lar biology, genetics, biomedicine and biotechnology) appeared, followed by appearance of numerous clinical subdisciplines. Also, there has been noticed a huge advancement in application of modern technology in medicine (e.g. ultrasound, electron microscope, magnetic resonance imaging, etc.). Such an enormous advancement in medicine (i.e. science and practice) requires further and continuous improvement of the language of medicine.

According to Pillegard (2000: 7) ...the English language with scientific and professional development is no longer a foreign language for other nations but it has become a lingua franca which used to be Latin once upon a time. English has become the lingua franca of medicine and most scientific fields since $95 \%$ of medical patterns come from English speaking countries.

\section{Medical communication}

The Oxford English Dictionary states that the word communicate comes from the Latin, meaning to impart, to share (https://en.oxforddictionaries.com/defini tion/communicate); so communication means conveying, exchanging ideas, etc. which is illustrated in figure 1 (fig.1, below).

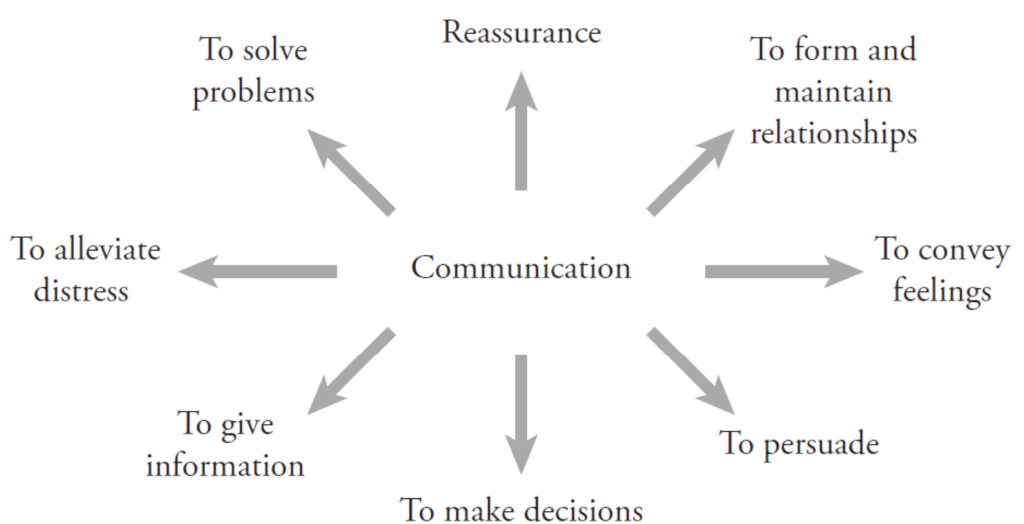

Fig. 1. Some purposes for communication (Loyd, M. and R. Box, 2006: 2-3).

The communication skill is necessary for health professionals because of many barriers unique for each medical profession (Hosley and Mole, 2006: 2). There are specific health care professional groups with whom health professionals must be able to communicate internationally (i.e. in EMP). Among these are: co-workers, physicians, managers, referral professionals and agency personnel and obviously while doctors are concerned - their patients. 


\section{The new paradigm for Medical English teaching}

Today's global economy requires changing the paradigm for Medical English language teaching, because it demands career-specific language that includes workplace culture and jargon to assure safe and effective delivery of professional services and the ability to coordinate research across borders. Most of current methods of instruction in English commonly used for health care professionals focus primarily on English language itself and secondarily embed the medical terminology in lessons. These teaching strategies filled with medical terminology and not very complicated dialogues about visits to doctors' offices don't meet the needs of the profession. Melodie Hull (2004) who has developed a new methodology suggests a paradigm shift. According to the formerly mentioned author, Medical English ought to be taught from the perspective of medicine and health care first while vocabulary and structures should be reinforced secondly. A standard of practice should be as follows: teacher-tutors are required to be health professionals as well as language instructors. Tutorials as well as interactions include simple and complex medical practices (e.g. anatomy, pharmacology, physiology, treatment of various diseases, etc.). Medical English teaching requires a new and modern approach which will be presented in this paper. In accordance to Hull (2004) who follows the core components of research of the following researchers: Benner (1984), Prat (2002), and Pratt and Brookfield (2002). The western view of adult education is andragogy. Andragogy is based on two following concepts:

- The adult learner is self-directed and autonomous

- The tutor is rather a facilitator and consultant than presenter of a context.

It is assumed that the adult learner arrives to the classroom with a set of skills and a basic knowledge that will be enhanced by a new learning experience. Developmental learning theory is derived from the cognitive psychology and it is sure that adult students have already developed their own cognitive maps and strategies that will help them in interpretation of the world. They learn by doing and acquiring new knowledge and skills which they then associate with previous learning and experience.

Andragogy is especially relevant to Medical English teaching. Hull (2004) believes that Medical English cannot be taught either with the same methods or at the same levels as basic English teaching. Specific for each medical career, highly technical language must be based in context. The goal of learning English at this level is not to learn grammar or structures but to acquire and use the language and social relations of practice within the career. Pratt and Brookfield (2002) who did the research in this field in Canada, USA, China and Singapore found out that trades people found traditional learning in the classroom to be artificial and devoid of realities essential to career-specific language. This also applies to Medical English and curricula of this kind which require from the teachers to have a similar career back- 
ground to their students' backgrounds, as the language of medicine and health care is filled with technical and academic language as well as slang, colloquialisms, abbreviations and acronyms.

\section{4a. Teacher and student's motivation}

In accordance to Pratt and Brookfield (2002) it is believed that teaching is guided by the teacher's perspective on teaching. The formerly mentioned authors ask the question of what the teacher is trying to accomplish and from what perspective the accomplishment should be performed. Whether the teacher of Medical English is committed to teaching English or is he interested in medicine and health care and promoting the use or acquisition of English as a medium through which one practices medicine and health care.

Students' motivation vary accordingly to their motives. Obviously, students who pursue career-specific English courses are more successful than those who take them for other reasons (e.g. immigration). Generally speaking, medical students interested in learning Medical English are more motivated to learn, acquire and use language when the entire context of the learning is within the field of their interest, that is medicine and health care. All activities connected with learning are enormously enhanced by the opportunities provided by the Instructor (Tutor) and within the classroom which enables the exchange of ideas and medical/health care practices while using Medical English.

\section{Methodology of the new paradigm}

Methodology of the new paradigm must be organised in such a way that language acquisition will be a combination of behavioural and cognitive approaches. Tutorials ought to be composed in such a way as to be contextually and experientially based to provide the opportunities that the students will be ready to apply or use the language immediately. The author of this paper agrees with Hull's (2004) argument that Medical English speech and writing have their own style and set of rules and structures. Health professionals must read, write, interpret and give directions using a wide variety of abbreviations and acronyms that are extremely career specific. Medical English is also contextually based. It may even be said that it is a language of its own. Doctors and medical personnel use academic language interspersed with everyday speech and jargon of the workplace. It rarely is based on complete or proper sentence structures. Tutorials are interactive and promote exploration and discovery of language through discussions and exercises based on the focus of the tutorial. As it has been stated above, all tutorials are interactive and 
promote the use of the language immediately. The curriculum must be designed in such a way that subjects based on health care and medicine occupy the essential part of it. It follows an $\mathrm{X}-\mathrm{Y}$ format, where $\mathrm{X}$ - means a tutorial focussing on vocabulary, vocabulary presentation and acquisition, and $\mathrm{Y}$ - means applying the learning activities from the previous tutorial (which may be called repetition of knowledge) or applying the previously learned material in the context. The context may include: role-plying, filling in and reading real hospital charts and forms and assessment of them, use of medical equipment, visits to the hospital units which are accessible to medical students. Students are encouraged to try to search for synonyms and also to encourage each other for correction. The instructor in such situations as mentioned above must become the facilitator or the guide. Once the entire interaction is completed, the instructor will review with the group of students strong points and weaknesses of the given exercise (see: Krashen, 2002), and they all together (instructor and the students) will speak about the importance of comprehensible input which means that acquisition starts from hearing and continues with the need of possessing the language to communicate. The formerly mentioned author of The New North American Paradigm for Medical English, Melodie Hull (2004) appreciates the importance of an immersion or pseudoimmersion for the language learner, which is very difficult to achieve while not having an access to the so-called Medical Simulation Centres as it happens to take place in most, not only Polish medical schools (fortunately, there is one of the best equipped and best structured Medical Simulation Centres at Collegium Medicum in Bydgoszcz, Nicolaus Copernicus University in Toruń). Following Hull's (2004) advice to use pseudoimmersion in the form of having Medical English tutorials in Medical Simulation Centres, in the Department of Applied Linguistics we have just prepared the curriculum for the next academic year which will take students of Medicine of Collegium Medicum in Bydgoszcz, Nicolaus Copernicus University in Torun to practice their English skills during the $2^{\text {nd }}$ year of studies in The Medical Simulation Centre.

Pratt and Brookfield (2002) identify a number of perspectives on teaching in adult education. In the presented here paradigm the tutors are expected to be the experts to the context they teach. This is important for the teaching of Medical English as students expect the context credibility. This paradigm demands a lot of additional work on tutors' side in order to acquire proper medical knowledge that would be comparable to the students' knowledge.

There is also apprenticeship perspective (Pratt et al., 2002) which reflects teaching outside the classroom. It is a process of enculturating the learner to a specific community. Language in context is very important for this highly specialized career- specific focus.

According to Pratt and Brookfield (2002) ...The Nurturing Perspective is the philosophical underpinning for adult education in North America for at least 25 past years. This perspective theorizes that self-concept and self-efficacy are fundamental 
to the ability of the learner to learn or to even believe that that he/she can learn (the learners want to become confident that learning the material will be useful to their lives. (Pratt et al., 2002: 49).

Some concluding remarks concerning the Collegium Medicum in Bydgoszcz, Nicolaus Copernicus University in Torun, the Department of Applied Linguistics where the author of this paper works concern the paradigm I have just presented. It needs to be stressed here that two of my colleagues who work as full-time assistants, teaching Medical English specialize in pure medical professions. One of them is taking post-graduate studies in neuordidactics, planning to continue with doctoral studies in English in the field of neurobiology, the other one has already finished the courses for dentistry assistants and planning to do her doctoral research in the field of neurolinguistics. Both of them are highly specialized university graduates of English departments holding M.A. degrees.

\section{Conclusion}

The New Paradigm for Medical English needs to shift from being contextually based to experiential. It needs to be delivered at the level of advanced English training where focus is dedicated to the language of the career and the context of the lessons needs to be relevant to the work the health professionals will be doing in the future. The provision of this type of course will improve student's motivation to learn and participate in learning activities. Following Hull's (2004) advice to use pseudoimmersion in the form of having Medical English tutorials in Medical Simulation Centres, we have just prepared the curriculum for the next academic year which will take students of Medicine of Collegium Medicum in Bydgoszcz, Nicolaus Copernicus University in Torun to practice their English skills during the $2^{\text {nd }}$ year of studies in Medical Simulation Centre.

Although it will take time in our country to redirect Medical English teaching to the new for us North American Paradigm it can be stated that we have already started doing it, although it is just the beginning of a great change that might take about 20 years to happen.

\section{References}

Benner, P. 1984. From novice to expert, excellence and power in clinical nursing practice. Menlo Park, CA: Addison Wesley Publishing Company.

Cockerham, W.C. 2016. Medical sociology. London and New York: Routledge; Taylor and Francis Group.

Dudley-Evans, T. And M.J. St. John. 1998. Developments in English for specific purposes. A multidisciplinary approach. Cambridge. Cambridge University Press. 
Friedmann, T.L. 2007. The world is flat: a brief history of the twenty-first century. New York: Farrar, Strauss and Giroux.

Hodges, B., and C.Segouin. 2008. "Medical education: it's time for transatlantic dialogue". Medical Education 42. 2-3.

Hull, M. 2004. Changing the paradigm for medical English language teaching. https://www.usingenglish. com/articles/changing-paradigm-for-medical-english-language-teaching.html. D.O.A. 09.08.2018.

Hosley, J. and E. Molle. 2006. A practical guide to therapeutic communication for health professionals. St. Louis: Elsevier, Inc.

Krashen, S. 2002. "The comprehension hypothesis extended" . In: Piske, T. and M. Young-Scholten (eds.). Input matters in SLA. Bristol: Multilingual Matters.

Kurtz, S., Silvermann, J. and J. Draper. 2006. Teaching and learning communication skills in medicine. Bingdon, U.K.: CRC Press, Taylor and Francis Group.

Lloyd, M. and R. Bor. 2006. Communication skills for medicine. Edinburgh, London, New York, Oxford, Philadelphia, St. Louis, Sydney, Toronto: Churchill Livingstone.

Micic, S. 2013. "Languages of medicine -present and future". JAHR 4.7. 217-233.

Cassell, E. 1976. "Disease as an "it": concepts of disease revealed by patients' presentation of symptoms". Social Science and Medicine 10. 143-146.

Crookshank, F.G. MD. 1923. "The importance of a theory of signs and a critique of language in the theory of medicine". In: Ogden, C. and I. Richards (eds.). The meaning of meaning. London/ $/ \mathrm{New}$ York: Harcourt Brace.

McCullough, L.B. 1989. "The abstract character of transforming and power of medical language". Soundings 72 (1). 111-125.

Mintz, D. 1992. What's in a word? The distancing function of language in medicine. Journal of Medical Humanities 13. 223-233.

Orr, T. 2002. "Introduction: The nature of English for specific purposes". English for Specific Purposes TESOL JOURNAL. 1-2.

Oxford English Dictionary, 2012. Oxford. Oxford University Press. (https://en.oxforddictionaries.com/ definition/communicate)

Pillegard, H. 2000. Reviews and perspectives in physiology. Cambridge: Cambridge University Press.

Pratt, D., S. Brookfield. 2002. Five perspectives on teaching in adult and higher education. Krieger Publishing Company, USA.

Silvermann, J., Kurtz, S. and J. Draper. 2016. Skills for communicating with patients. Croydon. CRC Press. Taylor and Francis Group.

Spencer, C. 2008. "Private Practice. Can we train eager young doctors without government involvement? "The Toronto Sun. 24 June 2008.

Swales, J. 1988. "Discourse, communities, genres and English as an international language". World Englishes 7.2. 211-220.

Widdowson, H. G. 1977. "The acquisition and use of language system" . Studies in Second Language Acquisition 2/1. 15-26.

Wood, A. 2001. "International scientific English; the language of research scientists around the world". In: Flowerdew, J. and M. Peacock (eds.). Research perspectives on English for academic purposes. Cambridge: Cambridge University Press. 71-83. 